\title{
INDICADORES DE BEM-ESTAR PARA POVOS TRADICIONAIS (IBPT): CENTRO DE UMBANDA XANGÔ DA MATA VIRGEM
}

\section{Welfare Indicators for Traditional People: Umbanda Xangô Center of the Virgin Woodland}

Everson Jaques Vargas (UNISINOS) Luiz Felipe Barbosa Lacerda (UNICAP)

Sueli Angelita dos Santos (UNISINOS) Adevanir Aparecida Pinheiro (UNISINOS)

Inácio José Spohr (UNISINOS)

João Batista dos Santos (UNISINOS)

Informações do artigo

Recebido em 28/02/2018

Aceito em 21/03/2018

$10.25247 / 2447-861 X .2018 . n 243 \cdot p 162-188$

\begin{abstract}
Resumo
Este artigo propõe analisar a aplicação dos Indicadores de Bem-estar para Povos Tradicionais (IBPT), no contexto do "Centro de Umbanda Xangô da Mata Virgem". Os IBPT possuem um arranjo de cinco capacidades, construídas a partir das narrativas dos próprios povos tradicionais. A organização dos procedimentos utilizados, na aplicação dos IBPT, teve como ambiente de sistematização o espaço do NEABI (Núcleo de Estudos Afro-brasileiros e Indígenas) - UNISINOS São Leopoldo. O texto nos guia para um estudo apurado sobre o funcionamento do Centro de Umbanda Xangô da Mata Virgem.
\end{abstract}

Palavras-Chave: Indicadores de Bem-estar para Povos Tradicionais. Centro de Umbanda Xangô da Mata Virgem. Povos Tradicionais. Capacidades.

\section{Abstract}

This article proposes to analyze the application of the Welfare Indicators for Traditional People, in this context, the Umbanda Xangô Center of the Virgin Woodland. The IBPT have a set of five Capacity for created from the narratives of the Traditional People themselves. The organization of the procedures used, in the IBPT applications, had as systematization environment the NEABI (Nucleus of Studies and Researchers in Afro-Brazilian and Brazilian.

Keywords: Welfare Indicators for Traditional People. Umbanda Xangô Center of the Virgin Woodland. Traditional People. Capacity. 


\section{Introdução}

A necessidade de remontar brevemente a história do Núcleo de Estudos Afrobrasileiros e Indígenas (NEABI) - UNISINOS ${ }^{1}$-, no início desse trabalho, possibilita-nos atender a um sério compromisso histórico com esse núcleo, que se dedica, há um largo período de tempo, à população negra e indígena da região. Reitera-se que foi este solo fértil que possibilitou o encontro com os povos de Terreiro - público alvo da aplicação dos IBPT.

O processo de construção do $\mathrm{NEABI}^{2}$ começou no final da década 1990, por meio de uma pesquisa realizada pelo CEDOPE (Centro de Documentação e Pesquisa) da UNISINOS, intitulada Cadastro dos Locais de Culto Religioso e Templos na região metropolitana de Porto Alegre - RS. Após a execução desta pesquisa, seus resultados trouxeram a articulação de um programa da universidade denominado Programa Gestando o Diálogo InterReligioso e o Ecumenismo - GDIREC, que tem como finalidade proporcionar espaços de conhecimento e reconhecimento, gerando o diálogo entre as múltiplas crenças religiosas do entorno da região.

No ano de 1999, a UNISINOS contratou uma profissional chamada Adevanir Aparecida Pinheiro, formada em Assistência Social, tendo vasta experiência com a comunidade local, buscando acompanhar o movimento de desenvoltura dos processos institucionais em relação à comunidade afrodescendente de São Leopoldo. No ano 2000 nasce o grupo Estudantes e Comunidades Afro da Unisinos - ECAU, sobre o gerenciamento de Adevanir Aparecida Pinheiro, com o objetivo de construir pontes entre a universidade e a comunidade afrodescendente de São Leopoldo e região.

Em setembro de 2001, o Centro de Ciências Humanas da Universidade criou o Instituto Humanitas Unisinos - IHU: o GDIREC e o ECAU passaram a integrar a Área de Teologia Pública deste instituto na universidade.

\footnotetext{
1 Atualmente o NEABI - UNISINOS é constituído pela Coordenadora e Professora Dra. Adevanir Aparecida Pinheiro; Professor Dr. Pe. José Ivo Follmann; Prof. Ms. José Inácio Spohr; Ms. Elisabeth dos Santos Natel; Prof. Ms. Jorge Luiz Teixeira. Graduado em Filosofia Cristiano Silveira, Graduada em Filosofia, Renata Moura. A formação do Núcleo possui uma profunda contribuição dos líderes religiosos, que foram os protagonistas na criação dos dois programas, ainda existentes no núcleo, além de outros profissionais como Débora Barbosa Bauermann que também protagonizou transformações dentro do núcleo, junto com líderes religiosos. Estes foram os profissionais que historicamente asseguraram muitos momentos históricos no protagonismo da construção histórica do NEABI e devem ser reconhecidos neste trabalho.

2 Grande parte deste resgate histórico é fruto do trabalho do Professor Dr. José Ivo Follmann - Professor de Pós-graduação da UNISINOS -, intitulado Apresentação da História do Neabi, 2009.
} 
No ano de 2003, surgiu, então, na ramificação do GDIREC, o GPAC - Grupo Permanente de Aprendizagem Coletiva, que trazia como vertente o apoio às práticas sociais de uma Casa de religião específica da região de São Leopoldo/RS. Esse grupo esteve em funcionamento do ano de 2003 a 2005. Seguindo o término do GPAC, inaugura-se então um grupo denominado grupo cidadania e cultura religiosa afro-brasileira. Esse grupo ainda está em pleno funcionamento atualmente.

Em 2007, o "grupo cidadania", tão carinhosamente chamado pela comunidade, cria o curso de inclusão digital para afrodescendentes, formando semestralmente dois grupos de pessoas, em cursos de 40 horas de duração.

Então, no ano de 2008, suprindo as demandas que o GDIREC mantinha sobre as temáticas afrodescendentes, criou-se um núcleo independente, envolvido com as áreas de pluralismo cultural e das relações étnico-raciais, e esse núcleo foi chamado de NEABI UNISINOS.

Entendemos que a necessidade de arquitetar a história desse grupo, promove ao leitor deste trabalho uma grande aproximação, elucidando o lugar e o povo que a visamos estudar mais profundamente. Deve-se ao $\mathrm{NEABI}$, os profundos créditos pelos vínculos criados com os povos de Terreiro tradicional da região, sendo esse o disparador para uma aproximação inicial e para a nossa investigação a seguir.

O histórico do contato das populações tradicionais com a cultura ocidental hegemônica - europeia - acarretou prejuízos, expropriações e violências a tais povos que ainda nos dias atuais, seguem vitimados por mecanismos explícitos e/ou subliminares de produção de ausências, exclusões ou inclusões perversas. (SAWAIA, 2005; SANTOS, 2007).

Uma das formas de oposição a estas injustiças históricas e atuais estão representadas no potencial dos índices e indicadores de qualidade de vida, utilizados de maneira geral para retratar tais populações, e que, ao final, usualmente tornam-se material subsidiário de políticas públicas e ações sociais para tais povos. (ACOSTA 2013; LACERDA, 2016).

Contudo, revisando os índices avaliativos dos mais variados órgãos de apoio, controle ou fomentos nacionais e internacionais, concluímos que apesar de alguns avanços, eles ainda são ineficazes para a compreensão das realidades dos povos tradicionais na América Latina. (ACOSTA, 2013; LACERDA, 2016; LACERDA E ACOSTA, 2017).

Sob essas percepções e apoiados em resoluções nacionais e internacionais desencadeadas por organização e pressão de algumas lideranças desses povos, como a 
Declaração dos Direitos dos Povos Indígenas (ONU, 2009)3 e Pacto de Pedregal4 (ONU, 1995), Decreto $4887 / 03^{5}$ sobre a demarcação desses territórios, etnoeducação, entre outros; é que nascem os Indicadores de Bem-estar para Povos Tradicionais (IBPT).

Os pressupostos iniciais dos IBPT estão assentados sob a preocupação da soberania das populações tradicionais em seus próprios territórios, assumindo que frente a qualquer intervenção, seus valores e culturas devem ser percebidos como parte fundante no decorrer dos planejamentos iniciais às avaliações finais. (Lacerda, 2016).

Para os povos tradicionais por nós estudados, Bem-estar encontra-se sob o equilíbrio entre a intervenção do povo e o meio onde intervém. Portanto, um conceito de condições espirituais e materiais de harmonia com a natureza que acaba por gerar uma série de acordos comunitários, comportamentos e percepções voltadas para certo estilo de vida.

Os IBPT apoiam-se em cinco capacidades elencadas a partir das narrativas dos próprios povos tradicionais:

a) Capacidade de Controle Coletivo do Território;

b) Capacidade de Agenciamento Cultural Autônomo;

c) Capacidade de Garantir Segurança Alimentar e Saúde;

d) Capacidade de Construir um Ambiente Tranquilo e;

e) Capacidade de Autocuidado e Reprodução. Essas cinco capacidades subdividemse em vinte indicadores sociais, econômicos, culturais, ambientais e espirituais que, espelhados em perguntas metodológicas, nos possibilitam a construção conceitual do bem-estar para aquela população, naquele dado momento.

Dessa maneira, ao final do processo, cada comunidade, por mais complexa que seja, possuirá seu bem-estar específico, cada uma com a sua singularidade. Os IBPT, nesse cenário, mostram-se enquanto metodologia socioambiental capaz de auxiliar as comunidades na identificação e análise de suas vulnerabilidades e fortalezas, produzindo

3 Mais informações em: Declaração das Nações Unidas sobre os Povos Indígenas: perguntas e respostas. 2. ed. Rio de Janeiro: UNIC; Brasília: UNESCO, 2009. 80 p.

4 O Pacto de Pedregal foi firmado após a reunião de consolidação de algumas providências sobre os direitos dos povos indígenas. Em 1993 foi consolidado o ano Internacional dos Povos Indígenas. Mais informações em: http://www.nacionmulticultural.unam.mx/pactopedregal/. Acesso em: 19/01/2018 às 19h53.

5 Para um aprofundamento da questão, vide: http://www.camara.gov.br/sileg/integras/458204.pdf. Acesso em: $19 / 01 / 2018$ às $20 h 03$. 
uma leitura fidedigna da realidade local e, dessa forma, melhorando a qualidade de vida através do subsidio assertivo aos projetos e políticas públicas que se pretendem desenvolver.

Tal metodologia se alicerça no processo ascendente de melhoria, aperfeiçoamento e adaptações, através de suas capacidades essenciais e seus derivativos indicadores, vem sendo aplicada em conjunto com diversos povos tradicionais, principalmente no Brasil através do Observatório Nacional de Justiça Socioambiental Luciano Mendes de Almeida (OLMA) e seus múltiplos parceiros; e na Colômbia através do Sinchi - Instituto de Investigaciones Amazónicas.

O caso de aplicação dos IBPT que trazemos neste artigo refere-se justamente a uma dessas parcerias em território brasileiro entre OLMA e o Núcleo de Estudos Afro-brasileiros e Indígenas da Universidade do Vale do Rio dos Sinos (NEABI- UNISINOS), aliados às Casas de religião, de Umbanda e de matrizes africanas da cidade de São Leopoldo (RS), aqui especificamente relatada através do Centro de Umbanda Xangô da Mata Virgem.

Para isso, iniciamos com uma síntese da constituição das religiões da Umbanda e de matrizes africanas, em especial a Umbanda, no estado do Rio Grande do Sul, passando a sua análise no contexto da cidade de São Leopoldo, para, posteriormente, contextualizarmos o Terreiro tradicional aqui em foco e os resultados derivados deste processo de aplicação dos indicadores de bem-estar.

\section{A Umbanda no Rio Grande do Sul}

O seguinte estudo sobre a Umbanda no Rio Grande do Sul comporta uma assimetria elementar e rizomática, trazendo para a contribuição da Umbanda em solo gaúcho, uma discussão fomentadora, que é entender a diversidade intercultural dessa religião e expandila para o seu cruzamento com outros lados, a conhecida linha cruzada.

A Linha Cruzada contempla, no mínimo, três linhas (ou lados): o Batuque e/ou a Nação (Orixás), a Umbanda (Caboclos/as, Pretos-Velhos, Crianças, Ibejis) e a Gira e/ou Quimbanda (Exus, Pombagiras, Povo do Oriente, Povo Cigano). Cada uma delas possui seus rituais diferentes que se conectam (ou não) com as outras diferenças de cada lado (ANDRADE; MELLO; HOLANDA, 2015, p.23).

No desafio de contemplar a Umbanda e suas contribuições como crença, fé e expressão religiosa em território gaúcho, percorreremos brevemente a história do Batuque 
gaúcho ${ }^{6}$ e, logo em seguida, explanaremos sobre a criação da primeira tenda de Umbanda no Rio Grande do Sul, passando por pequenos dados desta que foi a precursora dos demais Centros em solo gaúcho.

Apesar de manter-se viva a história do Batuque gaúcho durante quase dois séculos, nota-se que há uma lacuna no que diz respeito a documentos fidedignos e construídos por pessoas que foram protagonistas dessa religião. O Rio Grande do Sul (RS) possui a população estimada em 11.322.895 (IBGE, 2017) e dentre estas, as que se definem enquanto adeptas da Umbanda e/ou do Candomblé não passam de 157. 599 pessoas, isto é, 1,3\% da população gaúcha.

Contudo, na prática das grandes e pequenas cidades do estado estima-se que esses números podem ser maiores, visto que há um forte preconceito regional existente a respeito das pessoas e das práticas religiosas alinhadas às matrizes africanas no estado. Muitas pessoas que vivenciam tal crença religiosa não se sentem seguras em se autodeclararem batuqueiras ou umbandistas.

Quando se busca escrever sobre a história das religiões de matrizes africanas no Rio Grande do Sul, agudamente ouve-se falar no nome do Príncipe Custódio7 e sua família, como a figura introdutora e protagonista dos rituais de Batuque no sul. Porém, há indícios de pesquisadores, Babalorixás e Ialorixás que mencionam a presença do Batuque no estado desde meados de 1833, conjeturando-se com a expansão do Candomblé na Bahia. (CARNEIRO, 1991).

Diante de alguns impasses documentais, avalia-se que pelo Rio Grande do Sul ter participado dos terríveis pedestais da escravização negra no Brasil, desde meados do século XVII, é provável que algumas expressões religiosas de matrizes africanas tenham aparecido bem antes do documentado, principalmente por negros oriundos do Rio de Janeiro em regime de escravidão e desembarcados no porto de Rio Grande, trazendo consigo tal prática religiosa, sua proliferação oral e ancestral pelo território.

6 Forma singular de nomear as expressões e rituais das religiões de matrizes africanas no Rio Grande do Sul. Para um breve diálogo, vide: PINHEIRO, Adevanir Aparecida et al. África e afrodescendentes no sul do Brasil: história, religião e educação - São Leopoldo: Casa Leiria, 2015.

7 Personagem de uma família imperial de Daomé (atual Benin) do final do século XIX, mais precisamente em 1897, que veio ao Brasil por um acordo político feito com a coroa inglesa. 
Foi apenas no início do século XX, mais precisamente em 1926, que se constituiu publicamente a primeira tenda de Umbanda no Rio Grande do Sul fundada pelo senhor Otacílio Charão ${ }^{8}$. No início, a Casa não possuía uma sede fixa, então se migrava de reunião em reunião, de acordo com a disponibilidade dos seus membros, mas foi no mesmo ano de sua fundação, frente ao comprometimento de seus integrantes, que em 1926 o Centro se fixou na Rua General Abreu n 497 , Cidade Nova, Rio Grande, RS.

É possível mencionar que o fundador da primeira Casa de Umbanda, denominada Centro Espírita Reino de São Jorge (CERSJ), tenha percorrido o território religioso carioca e trazido alguns ensinamentos da Umbanda e da Macumba para o Rio Grande do Sul. Há muita especulação e mal-entendidos gerados pela falta de escrituras e documentos que legitimem os cerimoniais efetuados neste Centro Espírita de Umbanda, porém, um pesquisador movido pela curiosidade em escrever e documentar a história da Umbanda no Estado promoveu a seguinte reflexão sobre o Centro, de acordo com Guimarães (2010, p. 1):

De sua origem até meados da década de 1970, o CERSJ seguia uma doutrina de Umbanda de Mesa Branca, com as seguintes características: era proibida a utilização de quaisquer instrumentos de percussão; os cantos só podiam ser acompanhados com o bater de palmas e/ou o pé no chão; era autorizada a incorporação de apenas dois Exus, no caso as entidades Exu Tiriri e Exu de Manegum; era proibido o uso de guias ou colares ritualísticos...; pessoas separadas ou divorciadas eram proibidas de fazerem parte do quadro de sócios ou de participarem na corrente de trabalhos mediúnicos.

Nota-se que a organização institucional do CERSJ era muito particular, contrastando com um entendimento singular dos seus membros sobre a doutrina umbandista. Outras informações também foram encontradas sobre o Centro, como a diferenciação de vestimentas entre homens, mulheres e crianças; a participação das crianças nas cerimônias; a contribuição particular de cada membro; o auxílio a membros que comprovassem as suas vulnerabilidades sociais e o horário de funcionamento, que se situava entre 20 hoo e a oohoo, pontualmente.

8 Otacílio Charão era natural de Santa Maria - RS - foi um profissional que exerceu suas funções laborais, em primeiro momento, na Marinha Mercante brasileira em 1916. Após 10 anos, retorna ao Rio Grande do Sul e inaugura na cidade de Rio Grande/RS, uma fábrica de doces e balas. No mesmo ano, funda o Centro Espírita Reino de São Jorge, que foi registrado em cartório em 1932. Mais informações em: https://registrosdeumbanda.wordpress.com/2010/og/o2/a-provavel-tenda-de-umbanda-mais-antiga-do-rs/. Acesso em: 28 dez. 2017, às 15h59. 
Outro local que ajudou a fazer história e marcou a territorialização da Umbanda no Rio Grande do Sul foi a Congregação dos Franciscanos Espíritas de Umbanda, fundada por Laudelino de Souza Gomes na Rua Lima e Silva, Porto Alegre, RS, em 1932. Ainda hoje possui sua sede nessa cidade. Esse local está registrado como o segundo Centro mais antigo do Rio Grande do Sul e foi responsável por aprontar outros tantos sacerdotes de Umbanda da grande Porto Alegre e do interior do Estado. Sobre a cerimônia de aprontamento temos a seguinte contribuição dos autores:

Dependendo do lado na religião, existem diferentes aprontamentos: há o apronte pelo lado da Umbanda (o Amaci de ervas), do lado do Batuque (que passa pelo bori e quatro-pés) e, ainda, o Amaci cruzado (que pode incluir o vinho, enquanto sangue, e também o próprio sangue de animais). 0 aprontamento é o processo iniciático na religião que, de certa forma, quebra com o dualismo entre, de um lado, o dado $($ dom) e, de outro, o feito (iniciação). É que a pessoa já nasce (vem de berço) com o dom: resta-lhe, portanto, desenvolver, aprontar-se na religião [...] O aprontamento na religião é algo constante: o corpo, a partir disto, está sendo composto por diferentes potências e este processo opera-se desde a primeira revelação, pelos búzios, de quem são os/as orixás da pessoa (ANDRADE; MELLO; HOLANDA, 2015, p.27).

Depois de aprontado na Umbanda ou na Linha Cruzada, o umbandista ou batuqueiro terá o direito de ter o corpo ocupado pela a entidade, e, portanto, essa terá o direito do axé de fala; ademais, o aprontado terá o direito de abrir a sua Casa de religião e ter os seus próprios filhos-de-santo.

De acordo com o IBGE (2010), entre os censos de 2000 e 2010 , aumentou $25,13 \%$ o número de pessoas que se autodenominam umbandistas no estado do Rio Grande do Sul. Somente a Federação de Umbandistas do Rio Grande do Sul (FAUS) em 2017 contabilizou mais de 3.000 Terreiros tradicionais filiados 9 .

\section{A Umbanda na cidade de São Leopoldo}

O munícipio de São Leopoldo situa-se a $32 \mathrm{~km}$ de Porto Alegre, fazendo fronteira com os munícipios de Estância Velha, Novo Hamburgo, Sapucaia do Sul, Portão e Gravataí.

\footnotetext{
9 Para mais informações, consulte o site da Federação Afro Umbandista e Espiritualista do Rio Grande do Sul, em: fauers.com.br.
} 
Atualmente, possui 214 mil habitantes, segundo o Censo Demográfico do IBGE de 2010. A cidade é conhecida como o berço da colonização alemã no estado; município em que chegaram as primeiras 39 pessoas oriundas da Alemanha no dia 25 de Julho de $1824^{10}$.

Nos dias de hoje, essa data é comemorada como o São Leopoldo Fest, trazendo à tona a forte influência e dominância da comunidade alemã na cidade.

Entre as 39 pessoas que desembarcaram na Feitoria de Linho-Cânhamo ${ }^{11}$ - atual Casa do Imigrante -, local onde foram abrigados anteriormente negros escravizados indígenas e açorianos - 33 delas se autodeclaravam evangélicas e 6 expressavam a fé católica. Diante da chegada desses imigrantes, o entorno sociocultural desta região mudou completamente, explicitando esta realidade ainda nos dias de hoje (FOLLMANN, 2015, p. 82).

De acordo com Follmann et al (2017, p. 23), a cidade de São Leopoldo dispõe de uma forma miscigenada de viver as religiões; são modos híbridos de vivenciarem os processos de identidade, adquiridos ao longo das relações religiosas experimentadas no meio urbano, multicultural, ainda que $66 \%$ da população leopoldense se autodeclare católica (IBGE, 2010).

Seguindo os números do censo, $12 \%$ da população se autodeclara luterana, anglicana; $12 \%$ consideram-se pentecostais e neopentecostais; $4,5 \%$ da população leopoldense se autodeclara sem religião; seguido por 2,6\% que se nomeiam espíritas, 1,2\% adeptos da Umbanda e religião de matriz africana, finalmente, $1,7 \%$ são representantes de outras religiões.

Percebe-se que, comparando os números oriundos das estatísticas federais - (0,3\%) com os números regionais, que chegam a 1,3\% da população do Estado, e os números municipais extraídos do IBGE, com uma série de limitações qualitativas diante dos resultados, avalia-se que o percentual de adeptos à Umbanda no município é de 1,2\% da população, sofrendo uma leve queda na comparação com o estado gaúcho, entretanto, segundo Follmann (2015, p. 85):

A partir de dados reunidos pela Associação Afro-Umbandista de São Leopoldo e pela Associação Leopoldense de Candomblé, Umbanda e Cultos

${ }^{10}$ Disponível em: http://www.jornalvs.com.br/_conteudo/2014/07/noticias/regiao/66746-o-desembarque-dosprimeiros-imigrantes-alemaes-no-brasil.html. Acesso em: 21/12/2018 às 23h37

${ }^{11}$ FOLLMANN, José Ivo; PINHEIRO, Adevanir Aparecida. Afrodescendentes em São Leopoldo: memória coletiva e processos de identidade. Ciências Sociais Unisinos 47 (2): 141-152 maio/agosto 2011. 
Afro-brasileiros (ALCUCAB), estariam em funcionamento no município aproximadamente 468 Casas de Religião Africana.

Em relação a esse dado, o professor Inácio José Spohr - professor da Universidade do Vale do Rio do Sinos/UNISINOS -, que está à frente do programa GDIREC - Gestando o Diálogo Inter-religioso e Ecumenismo pertencente ao $\mathrm{NEABI}^{12}$, traz uma contribuição precisa: se cada Casa de religião tiver 10 a 20 adeptos, já se ultrapassa o número de pessoas que se autodeclaram umbandistas no censo do IBGE de 2010. Este fato merece uma análise aprofundada, pois denuncia a dificuldade que os cidadãos leopoldenses enfrentam em se autodeclararem publicamente umbandistas.

É sobejamente conhecido o fato de que o grupo das Religiões AfroBrasileiras que, devido à sua herança histórica - aqui considero tão somente as existentes em São Leopoldo -, são numericamente sub-representação, principalmente quando se trata de dados emanados dos Censos. Isso porque nem sempre os adeptos desses credos encontram condições suficientes que permitam deixar inequivocamente clara sua pertença religiosa. Com frequência marcam a opção "católica" (religião dominante e socialmente mais palatável), quando efetivamente fazem parte da Umbanda, do Batuque ou mesmo do Espiritismo ${ }^{13}$.

Ademais, como bem salienta Spohr ao longo da versão digital do Observasinos, IHU ${ }^{14}$.

Pretos e pardos somam, portanto, $28,51 \%$ nestas casas, enquanto que os "brancos africanistas" (permita-nos que os designemos assim) perfazem $71,49 \%$. Por conseguinte, os dados do Censo confirmam, por um lado, que a grande maioria dos que frequentam religiões afro-brasileiras é formada de brancos e que, nestas mesmas casas, pretos e pardos participam em número que supera sua representatividade real na região. $E$, por outro, confirmam que as religiões afro-brasileiras não são religiões só de negros, mas também não confirmam a ideia de que sejam (absolutamente) brancas ${ }^{15}$.

O diagnóstico nos permite alcançar uma análise acentuada sobre as religiões de matrizes africanas e a Umbanda em São Leopoldo e o profundo processo de "embranquecimento" da cultura popular da cidade; processo esse que sistematiza a repetição da segregação de uma religião originalmente brasileira e fundada com o ideal de

\footnotetext{
12 Núcleo de Estudos Afro-brasileiros e Indígenas, pertencente à Universidade do Vale do Rio dos Sinos UNISINOS/ São Leopoldo - RS.

${ }^{13}$ Disponível em: http://www.ihu.unisinos.br/observasinos/vale/populacao/opcoes-religiosas-em-sao-leopoldo. Acesso em: 28 dez. 2017, às $22 \mathrm{~h} 33$.

${ }_{14}$ Observatório do Vale do Rio dos Sinos, pertencente ao Instituto Humanitas Unisinos.

${ }^{15}$ Ibidem.
} 
unificar os povos do nosso país. Em São Leopoldo, os recursos de negação da Umbanda são elevados, ficando nítida a interpelação das diversas culturas brasileiras que se expressam em uma esmagadora sobreposição de pessoas brancas umbandistas em relação aos negros e indígenas, visto inclusive que, somente $14 \%$ da população leopoldense se declara preta e/ou parda, de acordo com o censo do IBGE (2010).

A população negra ou parda é diminuta no contexto urbano - tratando-se de negros ou pardos umbandistas -, estamos nos referindo à produção de um gueto sociocultural e religioso, que ainda se dinamiza em tom de silêncio na cidade.

Parafraseando Follmann (2015, p. 91) "os tambores e atabaques continuam a tocar", entretanto, a cuidar, se os mesmos toques que hoje singularizam a resistência da Umbanda nos seus mais de 100 anos poderão novamente ser silenciados pelo som da sirene da injustiça.

A dificuldade em agenciar dados coesos sobre a história da Umbanda em São Leopoldo nos implicou buscar informações relevantes sobre a doutrina em um Centro destacado pela ampla maioria dos Babalorixás e das lalorixás, como o mais antigo da cidade, denominado Centro Espírita de Umbanda Pajé Peri, fundado por Mãe Jovelina ${ }^{16}$ em 20 de novembro de 1953 .

O Centro de Mãe Jovelina dispõe de 46 filhos e filhas, tem a descendência do primeiro Terreiro tradicional da região do Vale dos Sinos, o Terreiro do Pai Tupinambá e Pai Tupaíba, ambas as Casas de Umbanda inauguradas em 1936 em Sapucaia do Sul - cidade vizinha de São Leopoldo e berço da Umbanda nesta região do Vale do Rio dos Sinos.

Mãe Jovelina relatou que sofreu muita discriminação na região, por inaugurar o seu Terreiro em um bairro onde nem a Igreja católica tinha chegado. Conforme ela, os padres da época Ihe perguntavam o que ela queria inaugurando a sua Casa de religião em uma cidade que é referenciada pelo túmulo do Padre Reus ${ }^{17}$. Isso fez com que Mãe Jovelina continuasse com o seu Terreiro tradicional com apenas três imagens no seu panteão, motivada pelos desafios advindos da sociedade local e dos representantes religiosos da época.

\footnotetext{
${ }^{16}$ Sacerdotisa do Centro Espírita de Umbanda Pajé Peri e membro solene da União Espiritualista de Umbanda nos anos 60 a 80 .

${ }_{17}$ Padre nascido em Pottenstein - Alemanha -, no ano de 1868. Padre Reus é uma referência religiosa da região do Vale do Rio dos Sinos (entorno de São Leopoldo - RS) e teve o seu falecimento no ano de 1947. Hoje muitos devotos do padre vão até o seu Santuário para cumprir promessas religiosas. Mais informações em: http://www.asav.org.br/sobre-padre-reus/. Acesso em: 29/12/2017 às ooh39.
} 
As informações obtidas no Terreiro tradicional de Mãe Jovelina são preciosas e datam, talvez, a primeira vez que esse ícone da Umbanda da cidade de São Leopoldo abriu sua Casa para disponibilizar toda a sua sabedoria de vida e religiosa na cidade. Com isso, registramos algumas frases proferidas por Mãe Jovelina durante a visita que realizamos no dia 05 de setembro de 2017:

- A minha Umbanda é assim: "só entra quem quer".

- Todas as religiões são boas, nós que somos ruins.

- A matéria é fraca. As pessoas passavam dificuldade para vir receber caridade. Caminhavam até 5 horas por dia pelo meio do mato para chegar aqui.

- Falta união na nossa religião.

Diante de tanta riqueza reunida em palavras, comenta-se que Mãe Jovelina, considerada a maior referência viva da Umbanda em São Leopoldo, aprontou para religião de Umbanda, a grande maioria dos sacerdotes da cidade, inclusive, possuindo uma ligação de ancestralidade muito forte com o Centro de Umbanda Xangô da Mata Virgem.

Entre essas sombras e clarões se constitui a história e a atualidade da Umbanda na cidade de São Leopoldo; processo que se mescla com o próprio movimento de resistência cultural e religiosa da população negra em território predominantemente alemão.

\section{O Centro de Umbanda Xangô da Mata Virgem}

A aplicação dos Indicadores de Bem-estar para Povos Tradicionais foi realizada dentro do espaço do Terreiro tradicional. Iniciou-se no dia 08 de agosto de 2017 e permaneceu até o dia 29 do mesmo mês, sendo a aplicação composta por mais de 8 horas de entrevistas gravadas, fotos, vídeos e participações nas cerimônias. Assim, tivemos o cuidado de respeitar o saber oral e ancestral de cada integrante do Centro de Umbanda, que se propôs trazer o maior número de representantes possível para responder às perguntas.

O Centro de Umbanda Xangô da Mata Virgem, fundado em 1997 por Sueli Guiomar dos Santos, é um Terreiro tradicional que está situado na cidade São Leopoldo; bastante conhecido na região como o "Terreiro dos irmãos", devido a sua constituição formada por irmãos de ventre. 
Atualmente, o sacerdote da Casa é reconhecido como Pai Batista, que oferece a sua matéria para o trabalho do caboclo ${ }^{18}$ Oxóssi das Matas, que sobre a doutrina ensinada por Xangô da Mata Virgem ficou responsável pela manutenção e direção dos trabalhos espirituais, após o falecimento da médium Sueli Guiomar dos Santos. Ele representa a autoridade política do Templo religioso, que é eleita pela herança da ancestralidade. Nesse caso, a fundadora da Casa e antiga sacerdotisa o escolheu com o auxílio das entidades espirituais. Assim, em ordem hierárquica, seguem: o subchefe, a mãe-pequena, cambono e os filhos da Casa ${ }^{19}$.

Os outros membros que compõem o Terreiro tradicional são responsáveis por gerir e seguir as normativas e regulações da Casa de religião, atuando na construção dos dias festivos, cerimônias, projetos culturais, serviços sociais e pela caridade ${ }^{20}$.

Portanto, a centralidade da gestão e da condução espiritual é desempenhada pelo sacerdote e sua entidade, que, na crença umbandista, é o chefe da Casa e detentor da última palavra hierárquica. Contudo, o Terreiro possui uma organização coletiva que visa o desempenho das atividades e debates de deliberações, situando todos os responsáveis irmãos e filhos-de-santo - que se responsabilizam em buscar apoios e parcerias para manter a Casa funcionando.

O Terreiro tradicional não possui personalidade jurídica ou associação com alguma federação, porém possui um CRAR (Certificado de Registro de Associação Religiosa) junto à

${ }^{18}$ Divindades, mais conhecidas pela sua falange indígena no Brasil, contêm um vasto conhecimento de ervas, plantas e chás. Responsáveis pela propagação espiritual da medicina tradicional indígena e pela cura de enfermidades.

${ }^{19}$ Sacerdote: Zelador do Templo religioso, guardião. Pauta o rito, através de uma tradição oral ele já está demarcado, é o responsável por regular o funcionamento do Centro, começar as orações em busca de purificação, receber a entidade que rege a Casa entre outras funções específicas. Subchefe: $2^{\circ}$ em comando, essa figura tem muita importância nas práticas da Casa de religião, ela destina os lugares para fazer as oferendas, despachos e trabalhos. É um auxiliar do sacerdote. Na situação dos irmãos, todos são os subchefes. Mães-pequena: São atribuições das pessoas, regidas por Oxum - somente mulheres - que fazem o trato com os orixás, são responsáveis pelos alimentos e pelos ornamentos do Templo religioso. Preocupam-se com a comida e as feituras da Casa. Cada um tem um dom, uma faz bolo, outra faz as oferendas, assim a Casa se permite existir. Cambonos: Podem ser homens ou mulheres, normalmente são mulheres, suas atribuições são: ajudar na serventia dos orixás, fazer o chamamento das pessoas nos horários de consultas e passes espirituais. Em alguns Terreiros tradicionais, os cambonos também são o subchefe, porém neste Terreiro específico não funciona desta maneira.

${ }^{20}$ É importante frisar que os integrantes de tal Casa de religião realizam atividades de caridade ao mais desfavorecidos, compreendendo estas ações como papel fundamental de sua atuação social, política, cultural e religiosa. 
Prefeitura Municipal da cidade de São Leopoldo, que a reconhece enquanto Templo de cultura religiosa tradicional.

Nota-se que o caboclo que rege a Casa atualmente (Pai Oxóssi), possui uma maneira ordeira de geri-la, eliminando as disputas aos cargos hierárquicos específicos, promovendo um envolvimento coletivo e uma harmonia decisória na administração do Templo. Dessa forma, somos levados a perceber que há um equilíbrio fecundo na Capacidade Coletiva de Organização sobre o Território.

Sobre a Capacidade de Agenciamento Cultural Autônomo, segundo pilar que subsidia os Indicadores de Bem-estar para Povos Tradicionais (IBPT), o Terreiro tradicional se localiza na zona urbana de São Leopoldo/RS, mais precisamente no Bairro Feitoria. Dentro do território da comunidade, não há lagos, nem rios, porém, no cruzamento do terreno do Templo e o pátio do vizinho, existe uma nascente de água que atualmente está canalizada pela parede que reparte os dois terrenos.

A Casa de religião possui duas extensões situadas nas cidades de Tramandaí/RS região litorânea do estado - e Taquara/RS (região metropolitana de Porto Alegre), ambas não possuem regulamentações legais, nem temos dados precisos para quantificar os seus perímetros atualmente.

A maior parte da residência/Terreiro da cidade de São Leopoldo é usada para o estabelecimento dos seus moradores, onde se alojam para seus afazeres domésticos. A outra parte - Terreiro - que corresponde a $30 \%$ do espaço da residência, é utilizada para a consolidação das práticas religiosas e para o atendimento ao público que procura por auxílio espiritual.

Identifica-se que, estando em um meio urbano, a sede do Templo religioso detém uma organização metropolitana adaptada à cidade. Já as outras extensões de terra apresentam uma geografia típica e se situam em regiões de praia e mata, correspondendo às tradições e às crenças da própria religiosidade umbandista.

De acordo com as narrativas proferidas pelos participantes da Casa de religião, a organização destes territórios (cidade, praia e mata) possibilita aos membros e servidores, a realização de festividades e serviços específicos de acordo com a demanda da época e do trabalho.

Notadamente se faz presente, nos relatos, a grande preocupação que os religiosos demonstram com a ecologia e a biodiversidade, cultivando, ainda em seus rituais, o respeito 
à natureza e as suas entidades espirituais. Mostra-se o significativo saber ambiental transmitido pela oralidade das práticas religiosas da Casa, fomentando a conservação e potencialização dos recursos naturais disponíveis na terra. Porém, a condição regulatória destes espaços, assinala certa vulnerabilidade, na medida em que se encontram territórios, que pertencem aos religiosos, sem disposições de regulamentações adequadas.

Para além destes espaços ligados à natureza, outros elementos se ligam diretamente à capacidade de gestar e reproduzir aspectos culturais autônomos, com a perspectiva de manter sua sede na cidade, sendo esta fixa e de propriedade do núcleo familiar que alicerceia a Casa de religião.

Sobre as dificuldades e interdições oriundas de invasões e conflitos por terras, indicador que sinaliza sobreposições e disputas por espaços e recursos dentro do território, o Terreiro tradicional não sofre com a sobreposição dos territórios latifundiários ou invasores, mas entende-se que, dentro desta análise, faz-se pertinente retomar a sobreposição discursiva que aparece dentro do meio urbano. Como o conflito com as religiões Pentecostais ${ }^{21}$ e Neopentecostais ${ }^{22}$.

Ao avaliarmos o potencial populacional e os fluxos migratórios, de acordo com as autoridades informantes, em 2017 o Terreiro contava com 25 membros. No ano de 2017 não houve nenhum nascimento e houve somente uma morte. Já no ano de 2015 a 2016, houve a morte da fundadora da Casa. Neste período houve 3 afastamentos ${ }^{23}$, que ainda, segundo os colaboradores, não são entendidos como desligamentos por conflitos com as práticas da Centro, e sim, por idade e outras circunstâncias. No entanto, houve 3 participantes que retornaram ao Templo religioso em 2017, mantendo a média populacional da Terreiro tradicional em 25 membros.

\footnotetext{
${ }^{21}$ Movimento de transformação e reavivamento espiritual oriundo de dentro do cristianismo, possuindo outra maneira de se relacionar com Deus, uma relação direta, o simbolismo do batismo no Espírito Santo. Para maiores informações, leia Souza (2002).

22 Para um debate apurado e com boas reflexões, vide Santos (2012).

${ }^{23}$ Faz-se necessário entender o que significa afastamento para os membros do Terreiro. Afastamento para os religiosos significa a entrega total das guias para o sacerdote e aos orixás, fato que não ocorreu nesses últimos anos na Casa de religião. Então, efetivamente, o Terreiro tradicional apresenta uma estabilidade dos seus membros, tanto ativo nas sessões, quanto frequentantes nos dias dos rituais. Isto possibilita que a Casa de religião se mantenha e se ramifique. Segundo os dados obtidos, houve um crescimento de 2 membros em relação ao ano anterior, indicativo que lhes permite avaliar o seu processo de crescimento.
} 
Analisamos também o grau de inserção dos seus participantes nas estruturas formais de ensino. Dentro do bairro Feitoria, estão presentes 7 escolas e 2 colégios - 2 de Ensino Médio e 7 de Ensino Fundamental. Neste ponto, há uma ampla cobertura do modelo formal de educação no bairro. O número de pessoas vinculadas à estrutura educacional chega ao total da população atual, isto é, $100 \%$ do povo de Terreiro.

Neste cenário, fica evidente a tramitação e a força do sistema formal de educação sobre a formação dos integrantes do Templo religioso, pois, desde muito cedo, os religiosos são ensejados a se autorreferenciarem com aquilo que já está posto hegemonicamente nos processos educacionais, valorizando muito pouco a sua cultura étnica, racial e religiosa. Apenas diante da lei 10.639/03, que foram inseridas algumas, não todas, discussões inerentes à história do negro afrodescendente e afro-brasileiro na escola formal e, por esse motivo, hoje temos uma estrutura curricular mais afetada por essa discussão, assim como algumas metodologias de ensino preparadas para trabalhar as origens étnicas e raciais do nosso povo brasileiro. (VEIGA, 2016, p. 76).

No que tange ao seu reconhecimento étnico-racial, o processo de identificação estabelecido pelo povo deste Terreiro tradicional se caracteriza e se identifica como umbandista espiritualista de linha branca; regidos pelo caboclo Xangô da Mata Virgem, Oxóssi e pelo orixá Ogum. Parte das relações intrínsecas e cotidianas que seus seguidores estabelecem com as entidades facilitam nas resoluções dos problemas dentro da Casa e também nos problemas da vida íntima de cada membro.

Outro elemento de identificação, mais explícito, refere-se à expressividade oral, pois ao serem formados e construídos dentro da Casa de religião, as pessoas detêm uma linguagem típica de quem habita a religião como modo de vida (FOLLMANN et al., 2017, p.27). No caso do Centro de Umbanda Xangô da Mata Virgem, 84\% dos membros alternam línguas entre loruba ${ }^{24}$, Tupi-guarani e Português.

O elevado grau de pessoas que oralizam e manifestam mais de uma língua é resultado da capacidade que os médiuns da Casa - pessoas que são usadas pelos orixás para que eles venham ao mundo trabalhar -, têm em incorporar e servir às entidades que chegam pelo

\footnotetext{
${ }^{24}$ Matriz linguística oriunda da África Ocidental (Senegal à Nigéria), trazida para as Américas no movimento escravista da diáspora africana. Mais informações em Rodrigues (2014, p. 117-143).
} 
toque do tambor ou por outro rito singular. Cada entidade -, entende-se "entidade" como linha vibratória próxima ao orixá, não o orixá em si - possui sua peculiaridade linguística e seus próprios movimentos. A linguagem típica de cada entidade representa uma significativa possibilidade de comunicação e articulação, entre ela e a sua falange nesse mundo. Isso legitima o reconhecimento da sua força pelos participantes dos ritos.

A possibilidade dessas entidades oralizarem a sua língua, seja ela loruba, Tupiguarani ou Português, abrem uma fenda significativa de troca e fortalecimento, fazendo a resistência dessa religiosidade perpetuar-se cada vez que uma entidade vem ao mundo dos humanos. Por fim, o alto índice de comunicabilidade ancestral na Casa de religião se apresenta como um facilitador, ampliando as possibilidades de laços afetivos e também, a confirmação de que aquelas entidades vêm a esse mundo trazendo a sua energia, seus valores, seu saber e espiritualidade, transformando o corpo do médium e os fluxos energéticos do Terreiro tradicional.

As análises construídas expressam que os membros do Templo religioso possuem uma ampla luta pelo reconhecimento da sua expressão de fé, étnico e racial. Faz-se então presente à afirmação de que todos os membros, como parte da Casa de religião, se autodeclaram umbandistas; como fator de análise, o núcleo gestor é formado por pessoas negras e de família de afrodescendentes da cidade de São Leopoldo/RS. Toma-se esta análise para pensar a importância da afirmação desse lugar para os religiosos, pois tal movimento tensiona a sociedade a mudar o seu modo de entender a Umbanda dentro do século XXI, principalmente visto o elemento cultural predominante de origem alemã, relatado anteriormente, na sociedade leopoldense (FOLLMANN et al., 2017, p.29).

O Terreiro tradicional enfrenta uma série de restrições frente ao direcionamento das suas atividades para a sociedade em geral, fator que justifica a necessidade do sincretismo, de acordo com Omolubá (2014, p. 14):

O Sincretismo na Umbanda é constituído pelo Africanismo, Cristianismo e Hinduísmo, recebendo, contudo, influência do Catolicismo e Espiritismo. Do Africanismo recebeu, para máxima devoção, o Ser Supremo OLORUM ou Zambi e apenas doze orixás do extenso panteon africano, assimilando-os integralmente; do Cristianismo, bebeu das primeiras águas do "Amai-vos uns aos outros" e "Fora da caridade não há salvação" e de outras sentenças crísticas atinentes a um comportamento fraterno universalista. Do Hinduísmo, a Umbanda aprendeu três Leis: Carma, Reencarnação e Evolução. 
Por fim, avançando na análise da Capacidade de Agenciamento Cultural Autônomo do Terreiro Xangô da Mata Virgem observamos suas festividades tradicionais: Festa de Oxóssi - 20 de janeiro; lemanjá - 2 de fevereiro; Ogum - 23 de abril; Preto Velho - 13 de maio; Xangô - 24 de junho; Cosme - 26 de setembro; Festa da Casa - 15 de novembro, Oxum - 8 de dezembro. Em todas as festividades do Centro são trabalhadas a importância dos alimentos, ritos, músicas e danças feita aos orixás e as entidades.

A principal festa do Templo religioso é comemorada no dia 24 de junho. Esta confraternização é realizada em saudação ao caboclo Xangô da Mata Virgem, por ser um ser de luz sábio e ordeiro. O Templo circula seus afetos e seu modo de funcionamento pelos poros da sua entidade regente. "Na festa de Xangô, todos sabem que não pode faltar uma boa comida e uma boa organização da Casa para prestigiá-lo", afirma uma filha da Casa.

Segundo os integrantes do Templo religioso, quando há outras festividades, exemplo: festa de lemanjá - dia 02 de fevereiro -, confraterniza-se com outros Terreiros tradicionais do estado e até do Brasil, saudando o/a orixá/iabá ${ }^{25}$ na beira do mar e realizando alguns rituais e oferendas na praia ${ }^{26}$. Vislumbra-se que nas outras práticas culturais do Terreiro, as matrizes de pensamento continuam sendo as mesmas, sempre promovendo a relação pontual entre a natureza e as entidades. Segundo a autoridade do Terreiro, Pai Batista: "o povo de Terreiro aproveita o sincretismo criado sobre lemanjá pela sociedade e então, promove a sua liberdade religiosa ao ar livre, com a participação da sociedade em geral".

Como citado anteriormente, tendo em vista que a Casa possui sede própria, apesar de alguma vulnerabilidade no registro de suas sedes em outros municípios, não possui risco eminente de invasão ou sobreposição em seu território; mantendo uma constância em sua população frequentadora - povo de Terreiro; está significativamente inserida nos circuitos educacionais formais da região, de maneira crítica e dialógica com seus próprios processos educacionais. Possui processos ativos e representativos de sua identidade religiosa, promovendo com empenho e sistematicidade suas festividades tradicionais; podemos afirmar que o Terreiro tradicional Xangô da Mata Virgem possui uma efetiva Capacidade de Agenciamento Cultural Autônomo.

\footnotetext{
25 Entende-se por labás, definição utilizada na Umbanda, para definir as divindades femininas.

${ }^{26}$ Outras festividades também são compartilhadas coletivamente com outros Terreiros tradicionais, como festa de Ogum, Cosme, Preto Velho.
} 
Devemos afirmar isto, contudo, sem perder de vista as resistências, exclusões e dificuldades enfrentadas, não apenas pelos integrantes desse Centro de Umbanda, mas por praticamente toda população umbandista da cidade e do Brasil. (BASTIDE, 1971). Como já referimos, processos esses desencadeados pela histórica cultura eurocêntrica de São Leopoldo, em parte, pela meteórica ascensão, nos últimos 20 anos, das religiões pentecostais e neopentecostais, em especial, aquelas que adotam o emblemático discurso da intolerância religiosa e demonização da crença do outro.

Um terceiro elemento que conjuntura o processo de Bem-estar de uma comunidade ou território tradicional, a partir da ótica dos IBPT, refere-se à Capacidade daquela população em Garantir sua Segurança Alimentar e Saúde.

Essa perspectiva transcende a usual expressão de seguridade alimentar, pois não visualiza os aspectos culturais de cada povo, observa exclusivamente às taxas de nutrição e balanceamento alimentar da população, tratando com irrelevante a qualidade do alimento, seus modos de aquisição, controle e armazenamento, assim como seu cabedal simbólico dentro do universo cultural. Por sua vez, Autonomia Alimentar transcende o espectro das necessidades básicas e observa qualitativamente os alimentos produzidos e consumidos a partir de uma ótica cultural e espiritual daquela população.

Os hábitos alimentares do povo de Terreiro são bem peculiares, usualmente, o arroz com galinha (normalmente se prepara o arroz e a galinha separados). Geralmente é um prato servido para as celebrações fúnebres, pois é prato de $\mathrm{Egum}^{27}$, e, não pode ser consumido em dias usuais. Outros pratos são de consumo aberto e natural ao longo da semana, sem quaisquer proibições alimentícias, nem restrições doutrinárias.

Os mantimentos, animais para os cerimoniais e os materiais para o funcionamento dos rituais da Casa são adquiridos no comércio local, fruto da industrialização desempenhada ao longo dos anos na região metropolitana. Dentro do território do Centro de Umbanda há plantio de poucos alimentos, apenas alguns chás e temperos para o consumo nos rituais religiosos tradicionais. A maioria dos insumos são comprados e consumidos logo em seguida,

\footnotetext{
${ }^{27}$ Eguns, para os umbandistas, são espíritos desencarnados que ainda não adquiriram um grau de consciência espiritual, muitas vezes nem sabem que estão desencarnados, percorrendo planos vibratórios terrenos. Em algumas situações, conseguem ligar-se a algum encarnado, tornando-se um obsessor espiritual para a pessoa e absorvendo a energia vital, por meio de vícios e pecados.
} 
pois os religiosos primam pelo sabor e pela acuidade dos pratos que são servidos aos membros da Casa, convidados e as entidades religiosas.

Partindo do princípio que a modalidade de plantio e cultivo não agenciam os meios de produção da Casa de religião no contexto urbano, nota-se que realmente o Terreiro não possui modos de cultivos no momento, porém dispõe de um grande potencial de terras cultiváveis e a garantia de sustentabilidade e segurança alimentar futura, caso necessário. Esta potencialidade se percebe analisando as extensões do Terreiro tradicional principalmente na cidade de Taquara (RS) - que não foram mensuradas - mas representam uma possibilidade de plantio e cultivo, já existindo inclusive um projeto em construção para esses fins.

A elaboração desses projetos não tornará a agricultura a principal fonte de renda e subsidio do Terreiro tradicional Xangô da Mata Virgem, mas proporcionará um novo modo de fazer religião e um escape das amarrações econômicas de mercado; o que hoje representa certa vulnerabilidade, pois se depende do recurso financeiro para aquisição dos elementos básicos requisitados à prática religiosa; ademais, corrobora para que as suas sacralizações tenham um contato mais íntimo com a natureza e um cuidado específico, fator com significativa carga simbólica às práticas religiosas do Terreiro tradicional.

Diante dos meios de conservação dos alimentos não se percebe, segundo os membros do Templo religioso, a necessidade de transformação e beneficiamento de qualquer alimento, pois realizam a compra dos produtos já prontos, facilitando o manejo e a utilização para as cerimônias. Da mesma forma, o armazenamento dos grãos da dieta do povo de Terreiro não se valida para a esfera privada e, sim, aloca-se nos equipamentos de armazenagem do comércio local.

Na medida em que observamos a dependência dos recursos financeiros para aquisição de insumos básicos para as práticas religiosas, podemos perceber algumas vulnerabilidades ligadas a Segurança Alimentar da Casa, que por hora, buscam sanar estes elementos através de uma previa organização que vislumbra uma melhor utilização dos terrenos disponíveis no interior.

Sobre a Capacidade de Construir um Ambiente Tranquilo, indicador este que assinala a dinâmica das relações que se constituem no território, baseando-se no respeito e na normatividade; assegurando os processos harmônicos de convivência. As narrativas expressam que já existiram conflitos entre as lideranças do Terreiro tradicional e um membro 
de outra religião, esse fato ainda gera um impasse no que diz respeito ao diálogo interreligioso. Porém, internamente, os religiosos manifestam que, na atualidade, o Templo religioso está bem integrado com os moradores locais, havendo uma relação de respeito à religiosidade dos componentes da comunidade urbana.

Todo e qualquer problema interno construído pelos membros do Templo religioso, por exemplo: as disputas de ego e poder, são solucionados e gerenciados pelo orixá chefe da Casa (Pai Oxóssi) que é conhecido dentre os umbandistas como o orixá ordeiro, conciliador, sábio e suntuoso. Outro fator importante é a promoção do diálogo entre irmãos que dirigem a Casa, que sempre foi enfatizado como princípio de funcionamento harmônico do Terreiro tradicional, mesmo antes do falecimento de sua fundadora - Sueli Guiomar dos Santos.

Ainda sobre algumas afetações externas, segundo o sacerdote da Casa, busca-se sensibilizar as pessoas sobre a temática do consumo de álcool e drogas. Frente a este trabalho preventivo, assinala-se que não existem casos crônicos registrados. Da mesma forma, a temática da sexualidade e da contaminação por DSTs (Doenças Sexualmente Transmissíveis) que é abertamente tratada com os membros, muitas vezes, em formações dentro das próprias reuniões do Centro de Umbanda.

Sendo, portanto, os membros, geridos por uma diretriz hierárquica espiritual que os orienta, harmonizando e solucionando os possíveis conflitos, segundo as regras da Umbanda e de seu orixá regente. Há diálogo, respeito e harmonia entre os irmãos sanguíneos que realizam a administração do Templo e deles com os demais frequentadores.

Podemos afirmar, que, internamente, existe uma significativa capacidade de consolidar um ambiente tranquilo para se viver dentro do Terreiro tradicional.

Por fim, no que se refere à Capacidade de Autocuidado e Reprodução, indicador que avalia desde o acesso à água potável, outros serviços públicos básicos até estruturas e pessoas que trabalham na saúde dos membros, aponta-se que geralmente o povo de Terreiro utiliza do abastecimento de água urbano, e, na falta desse, procura-se armazenar água na caixa de água - reserva para as situações de emergências que se encontram no território.

O Terreiro tradicional conta com um sistema de abastecimento de água disponibilizado pelo Serviço Municipal de Água e Esgoto em São Leopoldo, Rio Grande do Sul (SEMAE), que distribui água potável para toda cidade. Ademais, a constituição da sede do Terreiro conta com serviço de água encanada, esgoto, energia elétrica e coleta de lixo. Por 
estar inserido dentro do meio urbano, possui características similares às moradias da região, sendo adequado o nível de serviços básicos influentes na saúde de seus frequentantes.

Tratando-se de saúde, percebemos que existe um número relevante de frequentadores da Casa com quadros de hipertensão e anemia falciforme; aproximadamente, 15 integrantes dos 25 membros, números que retratam a constante luta que as autoridades da Casa de religião estabelecem contra a alimentação dos membros, construindo palestras, sempre que possível, sobre a saúde e bem-estar do corpo do médium. Diversas vezes, segundo os membros da Casa de religião, foram convidados profissionais para conversarem e orientarem o povo de Terreiro, sobre os cuidados com a saúde, física, mental e espiritual.

Sobre estes e os demais aspectos relativos à saúde, as pessoas e estruturas que podem prevenir doenças se utilizam de plantas e ervas da medicina tradicional de maneira complementar à medicina formal, sem conflitos entre ambos. Ademais, existem entidades que são referências nos casos da medicina tradicional, são elas: pretos velhos, caboclos e orixás. Além disso, a comunidade em que a Casa de religião está inserida conta com um uma unidade básica de saúde - UBS/COHAB - Feitoria -, que é utilizada por todos os membros da comunidade local.

É significativo o número de comunitários no bairro onde o Templo religioso está inserido que chegam até a Casa de religião buscando recursos complementares e espirituais para suas enfermidades, demonstrando o importante papel social que o Terreiro desempenha no campo da saúde e em seu entorno.

Frente à quantidade geral dos membros do Terreiro tradicional e suas atribuições religiosas - transes, possessões e incorporações - é considerável o número de pessoas apontadas como referências para atenção dos enfermos, chegando a 32\% dos membros atuais. Sendo assim, são consideradas fortes as práticas espirituais de enfrentamento às doenças emergentes dos membros do Terreiro tradicional e seus frequentantes.

Visto isso, percebemos que a Casa de religião Xangô da Mata Virgem apresenta uma boa capacidade em lidar com as enfermidades dos seus membros e da comunidade que a procura, adotando a medicina formal como amiga e cooperadorando no processo de cuidado e caridade da religião.

Referente ao processo de vir à vida, visto que os integrantes pertencentes à Casa de religião Xangô da Mata Virgem estão inseridos no meio urbano, não existe nenhuma parteira 
na Casa. Os cuidados antes e depois do parto, vacinas e registros são realizados pelo sistema formal de saúde. Em paralelo, as práticas religiosas, segundo o povo de Terreiro, regimentam o lado espiritual tanto da mãe, quanto da criança durante e depois da gestação. Dessa forma, neste ponto, o Terreiro tradicional responsabiliza-se pela proteção e o acompanhamento espiritual do feto e seus progenitores, mais uma vez, complementando-se com os cuidados da medicina formal.

A atenção pós-parto é desempenhada novamente pelas duas instâncias, sendo elas formais e religiosas. As práticas mais desempenhadas pelos religiosos, nesse quesito, referem-se aos banhos, orações e rituais de proteção.

Desta forma, a Capacidade de Autocuidado e Reprodução ofertada pelo Templo religioso aos seus integrantes e a população em geral, é extremamente adequada, trabalhando de maneira plural e aliada com as tratativas da medicina formal, garantindo a comunicação entre o serviço público básico e os cuidados tradicionais, estes, formalizados em sua sede para os participantes dos rituais.

\section{Conclusões}

Este breve artigo, que versa sobre o projeto de aplicação dos Indicadores de Bemestar de Povos Tradicionais (IBPT) no Centro de Umbanda Xangô da Mata Virgem, possibilitanos vislumbrar os desafios enfrentados pelos povos de Terreiro, tanto de Umbanda como das religiões de matrizes africanas em todo o Rio Grande do Sul. Desafios estes, que se acentuam em termos de exacerbação dos preconceitos e colocam as Casas de religião como protagonistas de uma luta, resistência e manutenção das culturas ancestrais da nossa própria história.

Tratando-se especificamente do Terreiro tradicional Xangô da Mata Virgem, percebemos que suas capacidades avaliadas são positivas, demostrando um harmonioso processo de Controle Coletivo sobre o Território; elementos significativos de Agenciamento Cultural Autônomo; normativas eficazes na consolidação de um Ambiente Tranquilo; elementos básicos satisfatórios e em comum acordo com os processos formais, garantindo uma boa Capacidade de Autocuidado e Reprodução. Demonstrando apenas parcial fragilidade na Capacidade de Segurança Alimentar e Saúde, contudo, essa, compreendida como equânime das Casas de religião que se localizam em território urbano. 
Por todos esses elementos somos levados a apontar que o bem-estar no Terreiro tradicional Xangô da Mata Virgem em São Leopoldo (RS) assenta-se sobre os laços da parentalidade, laços afetivos, organizacionais e espirituais entre os médiuns da Casa e suas divindades.

A Síntese das capacidades de Bem-estar do Terreiro tradicional Xangô da Mata Virgem pode ser visualizada na Figura 1.

Figura 1 - Síntese sistemática de cada Capacidade avaliada após a aplicação dos Indicadores de Bemestar para Povos Tradicionais.

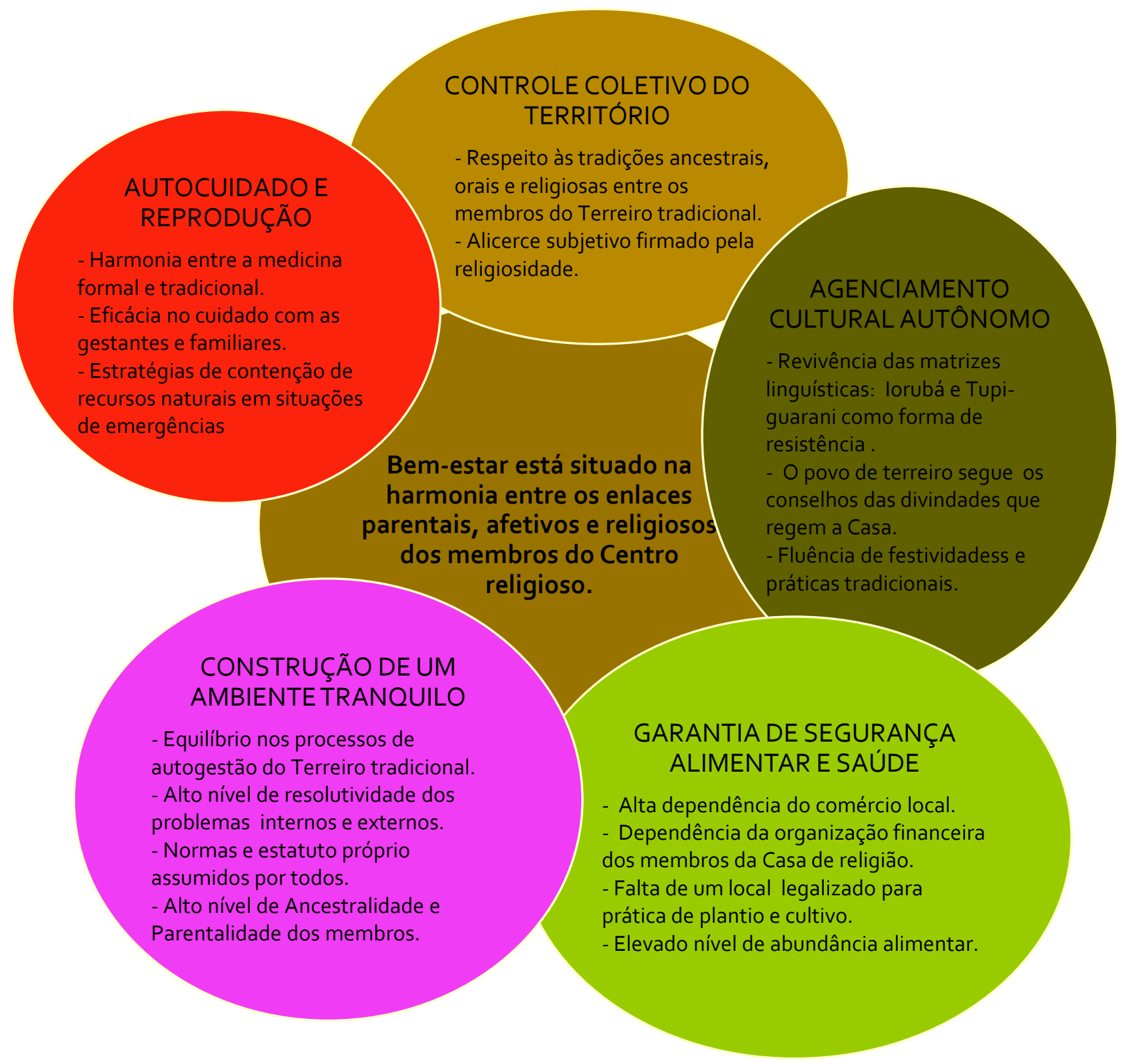

Fonte: Elaborado pelos autores 


\section{Referências}

ACOSTA, Luis Eduardo; LACERDA, Luiz Felipe. Indicadores de Bem-estar Humano para Povos Tradicionais: o caso de uma comunidade ribeirinha na fronteira da Amazônia brasileira. Revista Ciências Sociais Unisinos, 2017; V. 53.

ANDRADE, João Tadeu de. MELLO, Márcio Luiz. HOLANDA, Violeta Maria de Siqueira (orgs.). Saúde e cultura: diversidades terapêuticas e religiosas - Fortaleza: EdUECE, 2015.

BASTIDE. Roger. As Religiões Africanas no Brasil. São Paulo: EDUSP, v. 2, 1971, p. 371.

BIRMAN, Patrícia. O que é Umbanda. São Paulo: Brasiliense, 1983.

BRASIL. IBGE. Censo Demográfico, 2010. Disponível em: www.ibge.gov.br. Acesso em: 20/12/2017 às $14 \mathrm{~h} 55$.

BRASIL. IBGE. Características Gerais da População, Religião e Pessoas com Deficiência. Rio de Janeiro, p.1-215, 2010. Disponível em: www.ibge.gov.br. Acesso em: 21 de dez. 2017.

BRASIL. Lei n 9.394, de 20 de dezembro de 1996.Brasília, 1996.

BRASIL. Lei nº 10.639, 09 de janeiro de 2008. Brasília, 2008.

CARNEIRO, Edson. Religiões Negras: negros bantos. Editora Civilização Brasileira, 1991.

DECLARAÇÃO das Nações Unidas sobre os Povos Indígenas: perguntas e respostas. 2.ed. - Rio de Janeiro: UNIC; Brasília : UNESCO, 2009. $80 \mathrm{p}$.

DESEMBARQUE (O) dos Primeiros Imigrantes Alemães no Brasil. Disponível em: http://www.jornalvs.com.br/_conteudo/2014/o7/noticias/regiao/66746-o-desembarque-dosprimeiros-imigrantes-alemaes-no-brasil.html. Acesso em: 28 dez. 2017, às 20 30.

FOLMANN, José Ivo, et al. Processos de identidade, relações étnico-raciais e relações religiosas. Programa de Pós-graduação em Ciências Sociais; Centro de Cidadania e Ação Social; Núcleo de Estudos Afrobrasileiros e Indígenas; Universidade do Vale do Rio dos Sinos. - São Leopoldo: Casa Leiria, 2017. (Coleção NEABI; v.4. Refazendo laços e desatando nós).

FOLLMANN, José Ivo; PINHEIRO, Adevanir Aparecida. Afrodescendentes em São Leopoldo: memória coletiva e processos de identidade. Ciências Sociais Unisinos. São Leopoldo, v. 47, n. 2, p. 141-152, mai./ago. 2011.

FONTENELLE, Aluízio. A Umbanda através dos séculos. São Paulo: Editora Aurora, 1963.

BRASIL. Governo do Brasil. Pesquisa: População brasileira passa de 207,7 milhões em 2017. Publicado em: 30 ago. 2017, 12h55. Última modificação: 23 dez. 2017, 10h31. Disponível em: http://www.brasil.gov.br/cidadania-e-justica/2017/08/populacao-brasileira-passa-de-207-7-milhoesem-2017. Acesso em: 28 dez. 2017, às 11h52.

GUIMARÃES, Renato. A provável tenda de Umbanda mais antiga do RS. [S. I.], 2010. Disponível em: https://registrosdeumbanda.wordpress.com/2010/og/02/a-provavel-tenda-de-umbanda-maisantiga-do-rs/. Acesso em: 28 dez. 2017, às 16h32. 
HAAG, Carlos. A Força Social da Umbanda. Revista Pesquisa FAPESP. São Paulo, ed. 188, out., 2011.

LACERDA, Luiz Felipe. Por uma Sociologia das emergências: Perspectivas de emancipatórias nos territórios de ausências amazônicas. São Leopoldo, 2016. Tese (Doutorado em Ciências Sociais) Programa de Pós-Graduação em Ciências Sociais, Unisinos, São Leopoldo, 2016.

MOURA, Roberto. Tia Ciata e a Pequena África no Rio de Janeiro. Rio de Janeiro: Coleção Biblioteca carioca, 1995.

OLIVEIRA, José Henrique Motta de. Entre a macumba e o espiritismo: uma análise comparativa das estratégias de legitimação da Umbanda durante o Estado Novo. MPhilthesis. Rio de Janeiro: Universidade Federal do Rio de Janeiro, 2007.

OMOLUBÁ. Doutrina e práticas umbandistas: cadernos de Umbanda. Coordenação Diamantino Fernandes Trindade. São Paulo: Ícone, 2014.

ORTIZ, Renato. A Morte Branca do Feiticeiro Negro. 2. ed. São Paulo: Brasiliense, 1999. p. 17.

PINHEIRO, Adevanir Aparecida et al. África e afrodescendentes no sul do Brasil: história, religião e educação. São Leopoldo: Casa Leiria, 2015.

PRANDI, Reginaldo. O Brasil com axé: candomblé e umbanda no mercado religioso. Estudos avançados, v. 18, n. 52, p. 223-238, 2004.

RODRIGUES, C. C. Língua no Brasil: variação e multilinguismo. In: RODRIGUES, C. C.; LUCA, T. R.; GUIMARÃES, V. (Org.). Identidades brasileiras: composições e recomposições [online]. São Paulo: Editora UNESP; São Paulo: Cultura Acadêmica, 2014, p. 117-143. Desafios Contemporâneos collection. ISBN 978-85-7983-515-5. Available from SciELO Books. Disponível em: $<$ http://books.scielo.org $>$.

SANTOS, Boaventura de Sousa. A Crítica da Razão Indolente: Contra a lógica do desperdício da experiência. São Paulo: Cortez, 2007.

SANTOS, Milena Cristina. O Proselitismo religioso entre a Liberdade de expressão e o Discurso de ódio: a "Guerra santa" do Neopentecostalismo contra as Religiões afro-brasileiras. Brasília, 2012.

SAWAIA, Bader. As Artimanhas de Exclusão. Petrópolis: Vozes, 2005.

SILVA, Vagner Gonçalves Da. Candomblé e Umbanda: caminhos da devoção brasileira. Editora Selo Negro, 2005.

SOUZA, André Ricardo de. A livre religiosidade e a compulsória ciência do sociólogo da religião. Contemporânea - Revista Semestral do Departamento e do Programa de Pós-Graduação em Sociologia da UFSCar. São Carlos, v. 5, n. 2, p. 309, 2015.

SOUZA, Etiane Caloy Bovkalovski de; MAGALHÃES, Marionilde Dias Brepohl de. Os pentecostais: entre a fé e a política. Revista Brasileira de História. São Paulo, v. 22, n. 43, p. 85-105, 2002.

VEIGA, Claúdio Kieffer. Comunidades africanas no Brasil: a exclusão social e a diversidade cultural do povo de terreiro e sua proteção pela OIT. Curitiba: Juruá, 2016. 212p. 


\section{Everson Jaques Vargas (UNISINOS)}

Graduando de Psicologia e Educação Física/Licenciatura da Universidade do Vale do Rio dos Sinos UNISINOS. E-mail: everson.jaques@hotmail.com

\section{Luiz Felipe Barbosa Lacerda (UNICAP)}

Psicólogo; Doutor em Ciências Sociais. Professor da Universidade Católica de Pernambuco. Secretário Executivo do Observatório Nacional de Justiça Socioambiental Luciano Mendes de Almeida - OLMA. E-mail: olma@jesuitasbrasil.org.br

\section{Sueli Angelita dos Santos (UNISINOS)}

Assistente Social do Núcleo de Estudos Afro-brasileiros e Indígenas - NEABI - pertencente à Universidade do Vale do Rio dos Sinos - UNISINOS. E-mail: sueli.angelita@yahoo.com

\section{Adevanir Aparecida Pinheiro (UNISINOS)}

Assistente Social; Pós-doutorada em Ciências Sociais. Coordenadora do NEABI/Unisinos e professora da Universidade do Vale do Rio dos Sinos - UNISINOS. E-mail: adevanir@unisinos.br.

Inácio José Spohr (UNISINOS)

Possui graduação em Filosofia pela Universidade do Vale do Rio dos Sinos - Unisinos e mestrado em Ciências Sociais pelo Instituto Latinoamericano de Estudios Sociales, de Santiago do Chile. Coordenador do programa GDIREC - Gestando o Diálogo Inter-religioso e o Ecumenismo, pertencente aoNEABI/UNISINOS. E-mail: spohr@unisinos.br.

João Batista dos Santos (UNISINOS)

Possui graduação em História/Licenciatura pela Universidade do Vale do Rio dos Sinos - Unisinos. Sacerdote do Centro de Umbanda Xangô da Mata Virgem - São Leopoldo/RS. E-mail: jobatista2122@gmail.com. 